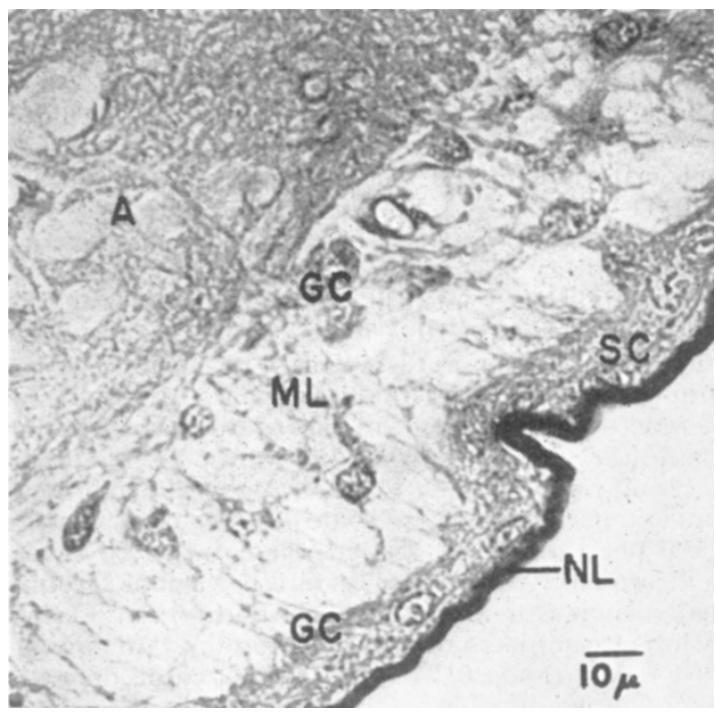

Fig. 1. Section through a thoracic ganglion of Periplaneta americana to show the region containing acid mucopolysaccharides. $A$, axons; $G C$, glial cells; $M L$, metachromatic layer; $N L$, neural lamella; $S C$, sheath cells

to the periodic acid-Schiff test. The metachromasy with toluidine blue is removed by incubation of the sections in hyaluronidase ('Hyalase'), but as this enzyme is not specific for hyaluronic acid, this does not give any information as to the nature of the acid mucopolysaccharide. An attempt is being made to characterize it biochemically.

The acid mucopolysaccharide forms a ground substance which resembles that of vertebrate connective tissue in its histochemical reactions, but the degree of chemical similarity remains to be determ. ined. The function of this layer of acid mucopolysaccharide is not apparent. There are suggestions that acid mucopolysaccharides can act as ionic barriers allowing cations to pass through, but restricting the passage of anions?. But it seems unlikely that this acid mucopolysaccharide forms an ionic barrier, both because it is restricted to the ganglia and because removal of the connective tissue sheath from either the ganglia or connectives results in the blockage of nerve conduction ${ }^{8}$. Wigglesworth ${ }^{5}$ suggests that the region might serve as a pool for nutrients, or as a means of maintaining the outer shape of the ganglion as changes in the state of nutrition alter the size of the cellular components of the ganglion. But, until more is known of the chemistry of this substance, it will be difficult to ascertain its function.

I am very grateful to Dr. A. G. Richards for his criticism of this communication.

Doreen E. Ashrurst*

Department of Zoology,

The University, Manchester, 13.

* Present address: Department of Entomology and Economic Zoology, University of Minnesota, St. Paul, 1 , Minnesota, U.S.A.

1 Ashburst, D. E., Quart. J. Micr. Sci. (in the press).

2 Pipa, R. L, and Cook, E. F., J. Morph., 108, 353 (1958).

Hess, A., J. Biophys. Biochem. Cytol., 4, 731 (1958).

- Pipa, R. L., Cook, E. F., and Richards, A. G., J. Comp. Neurol.,113, 401 (1959).

S Wigglesworth, V. B., J. Exp. Biol., 37, 500 (1960).

'Leblond, C. P., Glegg, R. E., and Eidinger, D., J. Histochem. Cytochem., 5, 445 (1957).

7 Kantor, T. G., and Schubert, M., J. Histochem. Cstochem., 5, 28 (1957).

Twarog, B. M., and Roeder, K. D., Biol. Bull. Woods Hole, 111, 278 (1956).

\section{Experimental Transmission of Borrelia anserina (Sakharoff 1891) by Aedes aegypti}

ThE causal organiam of spirochætosis, Borrelia anserina, was first reported from geese in the Caucasus, and has since been isolated from the blood of infected geese, turkeys, ducks, fowls, partridges, crows and sparrows from all parts of Africa, Australia, Austria, Bulgaria, Brazil, Egypt, East Indies, Germany, Greece, Hungary, India, the U.S.S.R., Rumania and Turkey.

The known common vectors of spirochætosis are various species of Argas and Ornithodoros.

Recent outbreaks in the Kaduna area of Northern Nigeria gave indications that the disease could be transmitted by other blood-sucking insects, and it was therefore decided to attempt experimental transmission of spirochrtosis with Aedes aegypti as this was readily available and was known to feed well on experimental birds. Laboratory-bred females were placed in plastic tubes with mosquito netting fixed at each end. This tube was held firmly on a bird (Rhode Island Red) that showed spirochrtes in a stained thin blood film. After approximately $45 \mathrm{~min}$. the tube was removed and the fully fed $A$. aegypti were separated from the unfed. After starving for several days they were then fed on clean birds. These birds were transferred to separate cages and thin blood films were taken daily. Control birds of the same age and breed were maintained under the same conditions and thin blood films were also taken daily from these birds.

The birds on which the $A$. aegypti had been fed developed a fever, became anæmic and showed spirochætes in their blood.

The control birds were normal throughout the experiment. Similar experiments are being carried out with Culex fatigans.

\section{J. A. Roberts}

Investigation and Training Centre, Ministry of Animal Health and Forestry, Kaduna,

Northern Nigeria.

\section{PSYCHOLOGY}

\section{Cross-modal Transfer in Man}

LiTTLE is known about transfer between different sensory systems during learning of complex material. Positive cross-modal transfer implies that learning to discriminate between a pair of stimuli in one modality leads to accelerated discrimination between the same stimuli presented in a second modality. Previous experiments showed no evidence for transfer between visual and tactile ${ }^{1}$, or visual and auditory ${ }^{2}$, discrimination habits in monkeys, although one investigation has been reported recently in which transfer between auditory and visual habits was obtained $^{3}$. In certain conditions, human subjects are able to match geometrically equivalent contours successively presented for visual and tactile comparison'. Auditory 'flutter' can similarly be matched with visual 'flicker' by subjects specifically instructed to equate rates of intermittance of sounds and lights ${ }^{5}$. Such cross-modal comparisons, however, are performed more poorly than intra-modal comparisons. A general theoretical argument against the immediate equivalence of perception in differing sense modalities has been presented by $\mathrm{Hebb}^{6}$. 